\title{
Thunderclap headache attributed to reversible cerebral vasoconstriction: view and review
}

\author{
Marcelo M. Valença • Luciana P. A. Andrade-Valença • \\ Carlos A. Bordini · José Geraldo Speciali
}

Received: 5 March 2008/Accepted: 20 June 2008/Published online: 31 July 2008

(C) Springer-Verlag 2008

\begin{abstract}
Thunderclap headache attributed to reversible cerebral vasoconstriction (THARCV) is a syndrome observed in a number of reported cases. In this article we reviewed this new headache entity (idiopathic form) using the clinical-radiological findings of 25 reported patients. In this series of patients $72 \%$ were women, the mean age at the onset of first headache episode was $39.4 \pm 2.3$ years. In addition to the sine qua non condition of being abrupt and severe (thunderclap) at the onset, the headache was usually described as being explosive, excruciating, or crushing. The feature of pulsatility, accompanied or not by nausea was described by $80 \%$ of the patients. Forty percent of the cases manifested vomiting and $24 \%$ photophobia. Usually the headache was generalized, and in three cases it was unilateral
\end{abstract}

M. M. Valença

Division of Neurology and Neurosurgery,

Department of Neuropsychiatry, Federal University

of Pernambuco, Recife,

PE, Brazil

M. M. Valença

Service of Neurosurgery, Hospital Esperança, Ilha do Leite,

Recife, PE, Brazil

L. P. A. Andrade-Valença

Service of Neurology, University of Pernambuco, Recife,

PE, Brazil

\section{A. Bordini - J. G. Speciali}

Department of Neurology, Psychiatry, and Medical Psychology, School of Medicine of Ribeirão Preto, University of São Paulo, Ribeirão Preto, São Paulo, Brazil

M. M. Valença ( $₫)$

Departamento de Neuropsiquiatria, CCS, Universidade Federal de Pernambuco, Cidade Universitária, 50670-420 Recife, PE, Brazil

e-mail: mmvalenca@yahoo.com.br at least at the onset. In 21 of 25 patients (84\%) there was at least one recurrence or a sudden increase in the intensity of the headache. A past history of migraine was present in 52\% of the patients. Precipitating factors were identified in $56 \%$ of the patients. Sexual intercourse was described by six patients. Of the 25 patients with THARCV syndrome studied, 12 (48\%) developed focal neurological signs, transitory ischemic attack $(n=1)$, or ischemic stroke $(n=11,44 \%)$, and two $(8 \%)$ of them manifested seizures. The THARCV syndrome is a neurological disturbance perhaps more frequent than expected, preferentially affecting middle aged female migraineurs, and having an unpredictable prognosis, either showing a benign course or leading to stroke.

Keywords Headache · Vasospasm - Stroke . Thunderclap headache $\cdot$ Pathophysiology $\cdot$ Criteria

\section{Introduction}

Thunderclap headache attributed to reversible cerebral vasoconstriction (THARCV) is a clinical-radiological entity observed in a number of cases reported since 1978 [1]. The THARCV syndrome may include several of the patients experiencing thunderclap headache [2-8], headache associated with sexual activity [2, 8-12], isolated benign cerebral vasculitis $[13,14]$, or migranous vasospasm or stroke [15-17].

It is widely accepted that the aura of a migraine crisis is associated with a vasoconstriction or vasospasm in the arterial territory of the aura-related cerebral cortex, which seems to be correlated with spreading depression, oligemia, or both [18-21]. In rare situations this arterial constriction is severe enough to cause brain ischemia [15-17]. Other conditions may induce much longer and 
intense cerebral artery narrowing [22-44], such as: subarachnoid hemorrhage (SAH; largely the leading cause of cerebral vasospasm) [22], drug abuse or sympathomimetic drug administration (methamphetamine, heroin, ephedrine, and cocaine) [23-25], intracranial surgical manipulation [26], head injury [27], herpes zoster [28], pheochromocytoma [29], eclampsia [30], ergot derivatives [31], angiographic contrast material [32], Lyme disease [33], systemic lupus erythematosus (SLE), periarteritis nodosa, primary granulomatous angiitis of the central nervous system (GACNS), and other types of cerebral arteritis [34-36]. Some of these disorders may course with headache as well.

Intracranial aneurysm rupture is a relative frequent event ( $\approx 10 / 100,000 /$ year) and it is very important to identify those high-intensity headaches of abrupt onset mimicking that of ruptured cerebral aneurysm. Primary thunderclap headache (4.6) and reversible cerebral vasoconstriction syndrome (6.7.3) are two clinical entities that may simulate a headache associated with subarachnoid hemorrhage [45]. The combination of both-thunderclap headache and reversible cerebral vasoconstriction-is being increasingly identified in a number of patients assisted in the emergency unit [44].

According to the IHS 2004 classification [45], the diagnostic criteria of primary thunderclap headache are the following: (A) severe headache fulfilling criteria B and C; (B) Both of the following characteristics: (1) sudden onset, reaching maximum intensity in $<1 \mathrm{~min}$; (2) lasting from $1 \mathrm{~h}$ to 10 days; (C) irregular occurrence over subsequent weeks or months and (D) not attributed to another disorder. The headache may recur within the first week after onset and a normal cerebrospinal fluid (CSF) and normal brain imaging are required.

On the other hand, the IHS 2004 criteria for headache attributed to benign (or reversible) angiopathy of the central nervous system are: (A) diffuse, severe headache of abrupt or progressive onset, with or without focal neurological deficits and/or seizures and fulfilling criteria $\mathrm{C}$ and D; (B) "strings and beads" appearance on angiography and subarachnoid hemorrhage ruled out by appropriate investigations; (C) one or both of the following: (1) headache develops simultaneously with neurological deficits and/or seizures, (2) headache leads to angiography and discovery of "strings and beads" appearance, (D) headache (and neurologic deficits, if present) resolves spontaneously within 2 months [45].

In the present article, we review the concept of this new headache syndrome (i.e., THARCV) using the clinicalradiological findings of 25 patients. Considering the management of patients with the THARCV syndrome, we shall discuss the diagnostic criteria and the differential diagnosis.

\section{Review of reported patients}

A Medline ${ }^{\mathrm{TM}}$ search was performed using the English keywords: thunderclap headache, explosive headache, sudden headache, headache and vasospasm. Patients with a clear history of thunderclap headache and angiograph confirmation of cerebral vasoconstriction were selected to be studied as a group.

In order to achieve a more uniform diagnosis of the THARCV syndrome we propose the diagnostic criteria listed in Tables 1 and 2. Since we consider the THARCV as a secondary form of headache attributed to the reversible cerebral segmental vasoconstriction it is further divided into (I) idiopathic, or (II) symptomatic headaches.

The medical literature until 2003 was reviewed, and 25 reported cases of patients (Table 3 ), including the one described by our own group, were selected according to the proposed diagnostic criteria for idiopathic THARCV syndrome (Table 2). Although several other cases were published in the recent years, we believe those 25 individuals represent a sample of the increasing number of THARCV cases described in the literature.

Analysis of the data shown in the Table 3 shows a profile of this particular headache subtype. In this series of patients, $72 \%$ were women, the mean age at the onset of first headache was $39.4 \pm 2.3$ years, ranging from 19 to 62 years (women, 26-62 years of age, mean $41.4 \pm 2.7$, median 38.5; men, 19-49 years of age, mean $34.1 \pm 4.2$, median 31.0). No significant difference in age was observed between women and men (Student $t$-test; $P=0.1665$ ). Eight percent of the patients were 1625 years of age, 28\% 26-35 years of age, 32\% 36-45 years of age, 24\% 46-55 years of age, and 8\% 56-65 years of age.

The characteristics of the headache described, in addition to the sine qua non condition of being abrupt and severe at the onset, differed according to patient description. The duration of the headache attack ranged from a short period of time, i.e., $10-15 \mathrm{~min}$, to as much as 34 weeks (Table 4). In approximately half of the cases the headache persisted up to 3 days. In one-third of the patients the pain continued for a few hours (less than $24 \mathrm{~h}$ ). The

Table 1 Proposed classification of reversible cerebral vasoconstriction syndrome as idiopathic or symptomatic

\begin{tabular}{ll}
\hline I & Idiopathic \\
II & Symptomatic \\
IIa & Associated with intracranial abnormalities other than cerebral \\
& vasoconstriction (i.e., aneurysm, vascular malformation, brain \\
& tumor, hemorrhage, venous thrombosis, etc.)
\end{tabular} 
Table 2 Proposed diagnostic criteria for thunderclap headache attributed to idiopathic reversible cerebral vasoconstriction (THARCV) syndrome

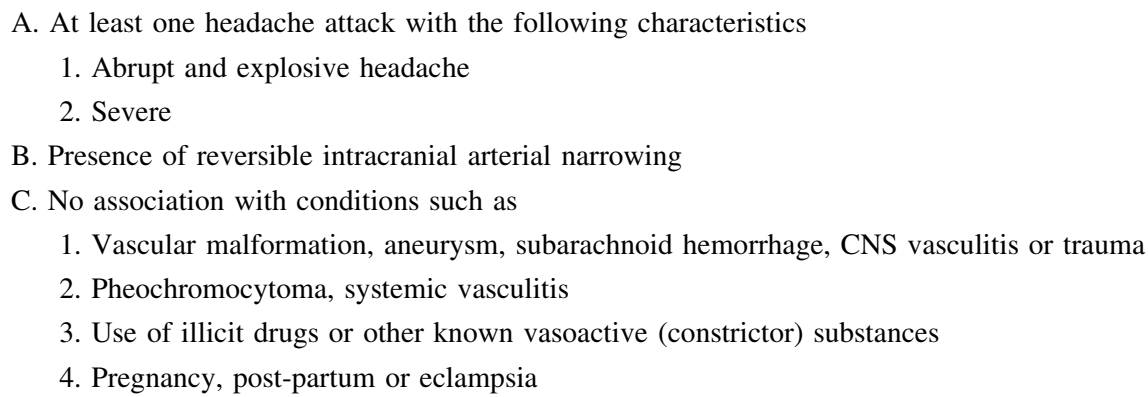

Obs.: the following characteristics when present strongly suggest THARCV syndrome: (a) female sex, (b) pulsating quality, (c) recurrence of headache, (d) precipitation or aggravation of the headache attack by physical or sexual activities, and (e) past history of migraine

quality of being explosive, excruciating, pounding, or crushing was registered. Other headache features were reported, such as throbbing, pulsatility, or pounding $(68 \%)$, being accompanied by nausea (44\%), vomiting (40\%), and photophobia (24\%). Furthermore, some of the patients manifested blurred vision $(8 \%)$. The headache was described usually as generalized (32\%) and bilateral; in three cases it was unilateral at least at the onset.

In 21 of the 25 patients $(84 \%)$ there was at least one recurrence or a sudden increase in headache intensity. Three or more recurrences were observed in five individuals (Table 4). The time interval between the first headache and recurrent attacks varied from a few hours up to 3 years. In 15 of 21 patients, recurrence was observed within the first week, and in one patient five such recurrences took place within this short period of time. In seven patients, recurrence was observed on the first day after the onset of headache. In three it occurred from 8 to 30 days. Two patients presented several headache recurrences within a $2-4$ year-period.

A past history of headache was present in 15 of the 25 reported cases (Table 4), including migraine in 13 patients $(52 \%)$, at least four of them with aura, one associated with hormonal contraceptives and another after headaches that had begun 8 years before during the first trimester of pregnancy.

Precipitating factors were identified by 14 patients (56\%; Table 5), with sexual intercourse being the major precipitating factor, reported by six patients $(24 \%)$. Of the 25 patients with THARCV syndrome studied, 12 (48\%) developed focal neurological signs, transitory ischemic attack $(n=1)$, or ischemic stroke $(n=11,44 \%)$, and two $(8 \%)$ of them manifested seizures. Two other patients presented seizures that were not related to stroke. Stiffness of the neck was observed in one patient.

Probably cerebral artery narrowing was present for several days after the onset of headache. In the different reports vasoconstriction was diagnosed by arteriography between two days and three weeks after the onset of headache in 18 of the reported cases. Even though the cerebral vasoconstriction was confirmed by angiography in all 25 patients, in the other seven cases the interval between the headache and the observed vasoconstriction was not informed. In seven patients a control angiography, performed 3-24 weeks later, was normal. In seven other patients a second angiography performed 2-32 weeks later demonstrated that most of the previously identified focal narrowing had resolved. In one case (patient \# 8 in Table 3) an arteriography done 16 days later still demonstrated diffuse arterial narrowing. In another patient (\# 9 in Table 3) an arteriography was repeated 15 days later showing normalization of the previously stenotic left internal carotid, but disclosing another arterial narrowing in the right internal carotid. Any of the intracranial major arteries can be affected; in one subject (patient \# 2 in Table 3) the external carotid artery was examined, disclosing involvement of the superficial temporal artery in addition to the presence of intracranial artery narrowing.

No drastic abnormalities were observed in the CSF of patient with THARCV syndrome, with the exception of an eventual increase in protein levels.

\section{Discussion}

In this article we described the clinical and radiological features of 25 reported cases of patients with a neurological syndrome characterized by THARCV.

The management of patients with the THARCV syndrome can be subdivided into pathophysiology determination and diagnostic and therapeutic strategies.

\section{Diagnosis and initial management}

The headache of the THARCV syndrome typically is of acute onset and increases abruptly in severity, reaching 


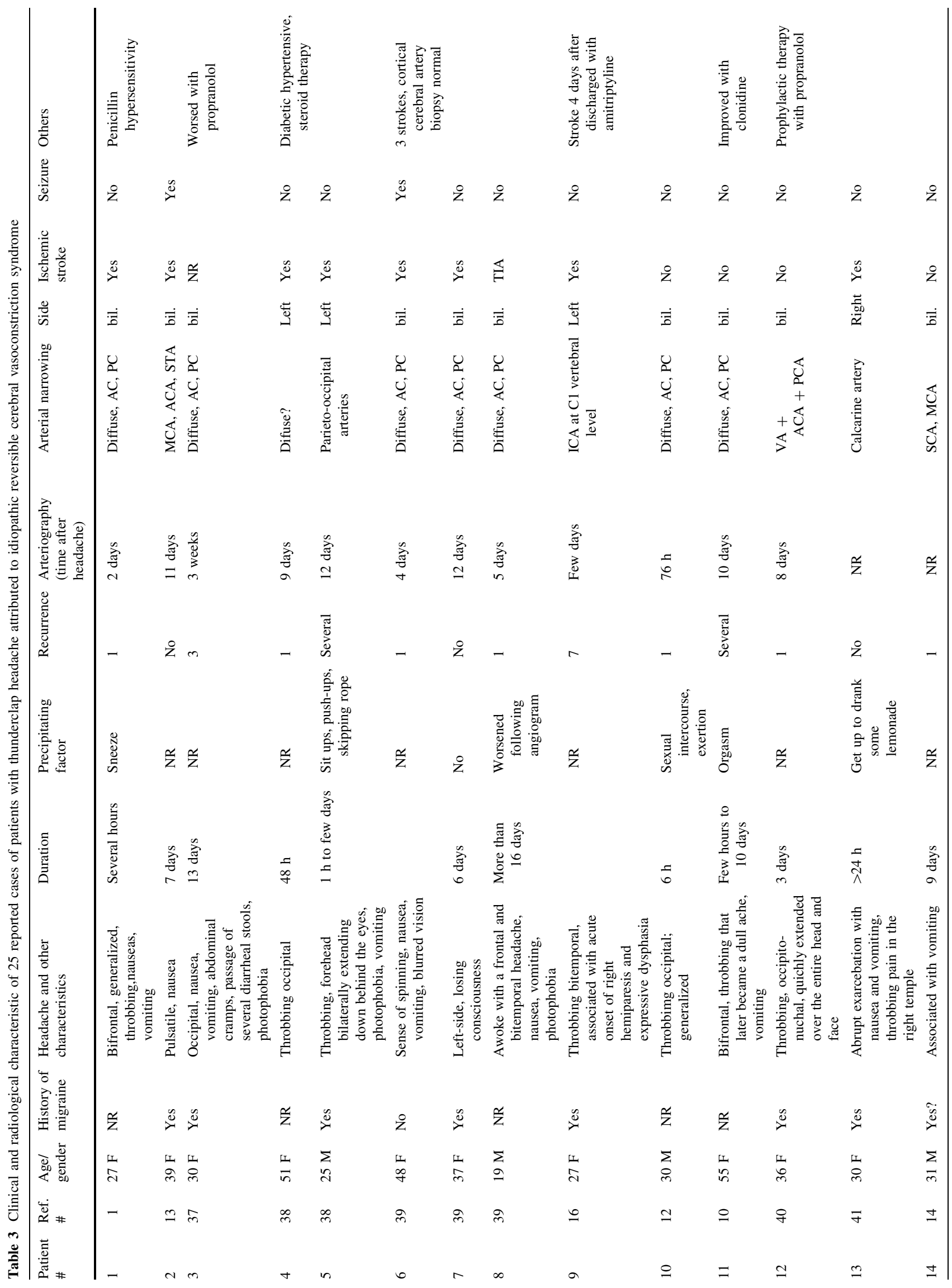




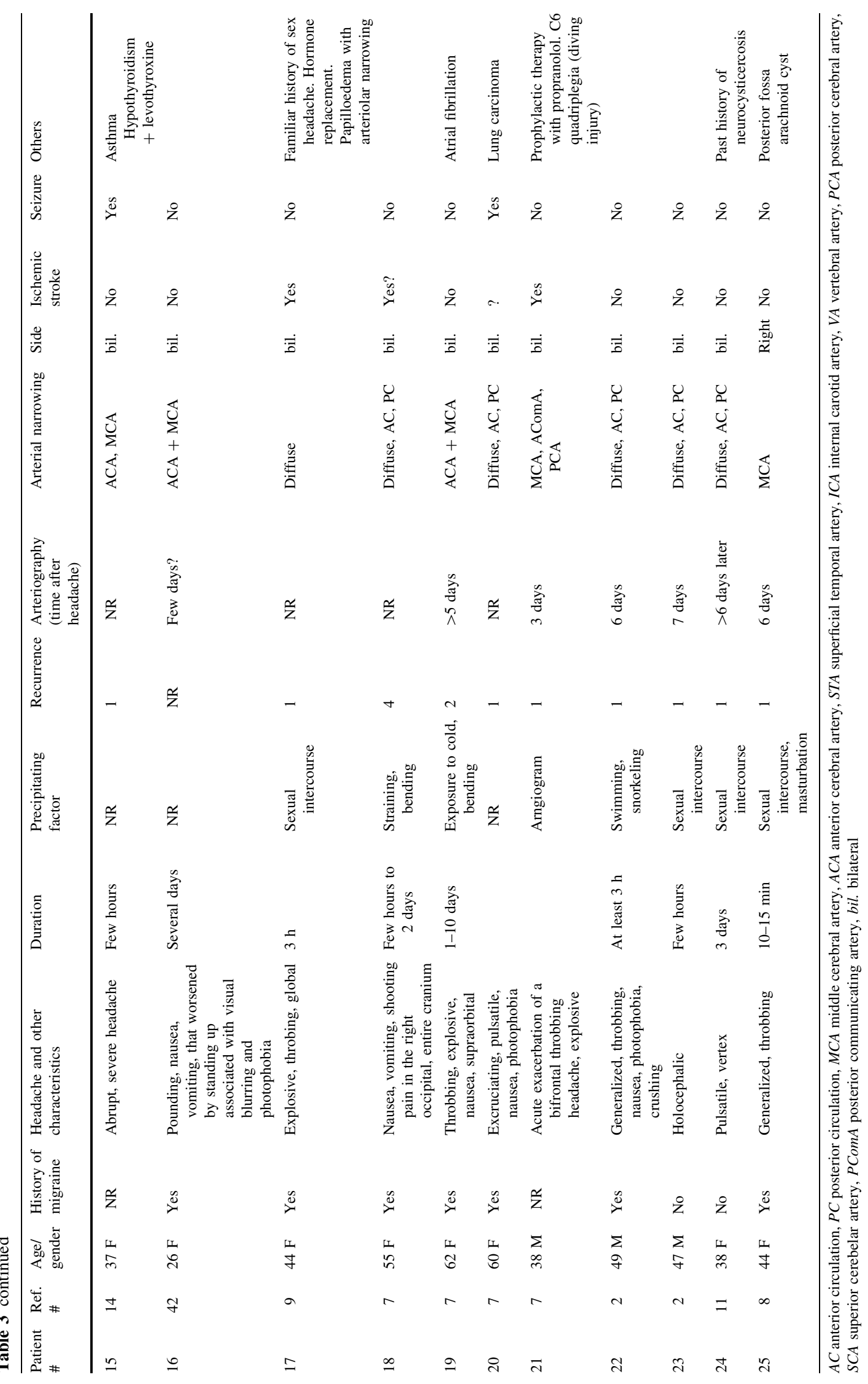


Table 4 Duration, location, characteristic, number of occurrence of the headache, and past-history of headache in the 25 patients reported with THARCV syndrome

\begin{tabular}{|c|c|c|}
\hline & $n$ & $\%$ \\
\hline \multicolumn{3}{|l|}{ Duration $^{\mathrm{a}}$} \\
\hline$<24 \mathrm{~h}$ & 10 & 40 \\
\hline $24 \mathrm{~h}-3$ days & 5 & 20 \\
\hline 4 days -7 days & 3 & 12 \\
\hline$>7$ days & 7 & 28 \\
\hline \multicolumn{3}{|l|}{ Location } \\
\hline Generalized & 8 & 32 \\
\hline Unilateral & 3 & 12 \\
\hline Frontal & 5 & 20 \\
\hline Occipital & 4 & 16 \\
\hline Fronto-temporal & 1 & 4 \\
\hline Temporal & 1 & 4 \\
\hline Vertex & 1 & \\
\hline \multicolumn{3}{|l|}{ Characteristic } \\
\hline Abrupt onset & 25 & 100 \\
\hline Severe intensity & 25 & 100 \\
\hline Throbbing, pulsatile, or pounding & 17 & 68 \\
\hline Nausea & 11 & 44 \\
\hline Vomiting & 10 & 40 \\
\hline Photophobia & 6 & 24 \\
\hline Explosive & 3 & 12 \\
\hline Blurred vision & 2 & \\
\hline Dull ache & 1 & \\
\hline Excruciating & 1 & \\
\hline Crushing & 1 & \\
\hline Sense of spinning & 1 & 4 \\
\hline Losing consciousness & 1 & \\
\hline \multicolumn{3}{|l|}{ Number of recurrences } \\
\hline None & 4 & 16 \\
\hline 1 & 15 & 60 \\
\hline 2 & 1 & 4 \\
\hline 3 & 1 & 4 \\
\hline 4 & 1 & 4 \\
\hline 7 & 1 & 4 \\
\hline$>7$ & 2 & 8 \\
\hline Past history of headache & $15 / 25$ & 60 \\
\hline Migraine & 13 & 52 \\
\hline With aura & 4 & 16 \\
\hline Without aura & 3 & 12 \\
\hline Unclassified & 6 & 24 \\
\hline Tension-type headache & 1 & 4 \\
\hline Associated with CCD & 1 & 4 \\
\hline Associated with pregnancy & 1 & 4 \\
\hline
\end{tabular}

$C C D$ contraceptive drug

a Some of the patients presented recurrent headaches of different duration
Table 5 Precipitating factors identified in 14 of the 25 reported cases of patients with THARCV syndrome

\begin{tabular}{lrr}
\hline Precipitating factor & $n$ & $\%$ \\
\hline Sexual intercourse & 6 & 24 \\
Exertion $^{\text {a }}$ & 5 & 20 \\
Angiography & 2 & 8 \\
Sneezing & 1 & 4 \\
Exposure to cold & 1 & 4 \\
Total number of patients & $14 / 25$ & 56 \\
\hline
\end{tabular}

${ }^{a}$ Activities defined as exertion were calisthenics (i.e., sit ups, pushups, and skipping rope), getting up from bed, straining, bending, swimming, snorkeling, and chasing off and screaming at an attacking $\operatorname{dog}$

peak severity in less than $60 \mathrm{~s}$ (thunderclap headache) [46]. The pain can be precipitated or aggravated by physical or sexual activities. The duration of the headache can be 5 min or longer. Thus, we propose some minor changes in the thunderclap diagnostic criteria modified by Dodick et al. [2]: (a) time to reach peak severity up to $60 \mathrm{~s}$; (b) headache duration of $5 \mathrm{~min}$ or longer, since the explosive type of headache occurring during sexual activity is considered to be a thunderclap headache [46] and may be of short duration. Even though the International Classification of Headache Disorders, 2nd edition (ICHD-II) criteria stipulate that the pain of primary thunderclap headache last from $1 \mathrm{~h}$ to 10 days (Code 4.6) [45].

We could subdivide the THARCV syndrome into idiopathic and symptomatic. The symptomatic THARCV syndrome should fulfill the A and B items of the proposed diagnostic criteria, and is categorized into four subgroups: (IIa) associated with intracranial abnormality (vascular malformation, aneurysm, subarachnoid hemorrhage, CNS vasculitis or trauma); (IIb) associated with systemic disease (e.g., pheochromocytoma or systemic vasculitis); (IIc) associated with drug abuse and use of vasoactive drugs (e.g., ergotamine, cocaine, heroin, methamphetamine, ephedrine, tryptans, intravenous use of contrast substances); or (IId) associated with pregnancy, post-partum or eclampsia. As exclusion criteria we consider the presence of systemic vasculitis or a central nervous system (CNS)meningeal biopsy showing inflammatory features related to CNS vasculitis.

More specifically, during the management of a patient with a thunderclap headache, as a general rule a CT brain scan without contrast is required. If a diagnosis is not made by this CT, lumbar puncture and CSF examination is mandatory during the acute phase to rule out any intracranial symptomatic lesion, particularly $\mathrm{SAH}$ and its causes. Both the CT scan and CSF are expected to be normal, with the exception of patients with stroke, cerebral 
edema, or intracranial hypertension, in which CSF abnormality is the result of these complications. Conventional cerebral angiography should be avoided, since the contrast medium could enhance the vasospasm and this, in turn, would increase the chance of a stroke or even cause the deterioration of a previously critical neurological condition, particularly in migraineurs $[16,47]$. The next step would be the request of a good-quality magnetic resonance (MR) angiography or angio-computed tomography (CT) of intracranial vessels as soon as possible, in such a way that any moderate to severe (reversible) vasoconstriction would be visualized. The conventional arteriography should be performed later, 3-4 weeks after the last severe headache attack. During the arteriography a study of the external carotid artery and its branches should be included in an attempt to find a segmental narrowing in a superficial artery. This could allow an easier (extracranial) approach to an eventual vessel biopsy.

Patients with thunderclap headache in the absence of cerebral vasospasm have been reported [48, 49]. This probably is factual, but the possibility of a short-lived cerebral arterial spasm occurring only at the onset of or during headache still needs to be excluded. Rothrock et al. [16] discussed why delayed arteriography would miss a transient spasm/stenosis to confirm migrainous stroke, to justify the lack of abnormality found in angiograms of patients who developed stroke during a migraine attack.

\section{Differential diagnosis}

The idiopathic THARCV syndrome is a disease with cerebral vasoconstriction. Hence, all the other possibilities that could provoke an intracranial arterial narrowing should be taken into account. The lack of systemic features enhances the possibility of a given arterial luminal narrowing to be part of the more benign THARCV syndrome when compared with CNS vasculitis, in which no resolution of the vascular disease is expected without adequate treatment. Although reversibility of intracranial arterial narrowing is anticipated in the THARCV syndrome it may take weeks to happen. Even though the reversibility of the vasoconstriction is not important during the initial diagnostic criteria, the reversibility of the condition needs to be proved, as the syndrome is called reversible. Since this has not always been made in previous studies as well as in IHS 2004 classification [45], the confirmation of the reversibility of the vasoconstriction should be included in the final diagnostic criteria, thanks to the reliability of less expensive or invasive techniques (e.g., angio-RM or angioCT).

In the discussion of some of the particularities that should differentiate the THARCV syndrome from other identified causes of arterial narrowing we may mention some features, particularly those concerning CNS vasculitis [37], a rare inflammatory disease of vessel walls associated with many causes (i.e., infection, malignancy, ionizing radiation, drug abuse, and autoimmune disease). Since angiographic features in cerebral arteritis are not completely specific, the associated radiologic and clinical findings often are fundamental elements for a diagnosis [34]. Narrowing of a vessel may be the result of spasm, edema, cellular infiltration, or proliferation of the vessel wall as well as compression by adjacent thickened meninges, exudates, or fibrosis [34].

Cerebral arterial narrowing might be subdivided into four groups: (1) vasospasm (contraction of arterial smooth muscle); (2) thickening of the vessel wall; (3) extrinsic compression; and (4) developmental or congenital [40]. Very probably the THARCV is a form of headache attributed to reversible cerebral vasoconstriction syndrome (benign or reversible angiopathy of the CNS, ICHD-II Code 6.7.3) [39, 45].

According to the IHS 2004 criteria for headache attributed to benign (or reversible) angiopathy of the central nervous system, a severe headache of progressive onset occurring during the clinical presentation of the syndrome is permitted [45]. In the present article we intend to study the thunderclap headache attributed to reversible cerebral vasoconstriction syndrome. Furthermore, we do not agree with the IHS D criterion [45]: "Headache (and neurological deficits, if present) resolves spontaneously within 2 months". It is well known that an ischemic stroke may course with permanent neurological deficit.

Mechanical, biochemical, or neurogenic causes may explain the arterial spasm. Vasoactive substances may cause vasospasm, such as chemical substances (ergotamine, amphetamine, cocaine), metabolite substances (in eclampsia or pheochromocytoma), and toxins (angiographic contrast material) [40].

In the group of autoimmune mediated diseases we may mention primary GACNS, SLE, polyarteritis nodosa, giant cell arteritis, and Sjögren syndrome. The physician should also search for other conditions that are known to cause vasculitis, such as drug hypersensitivity, cancer, infection, rheumatoid arthritis, and inflammatory bowel disease [36]. Noninfectious vasculitides can be classified on basis of the predominant type of vessel affected: large-vessel vasculitis (giant-cell arteritis and Takayasu's arteritis), mediumsized-vessel vasculitis (polyarteritis nodosa, Kawasaki's disease, and primary GACNS vasculitis), and small-vessel vasculitis (ANCA-associated small-vessel vasculitis, immune-complex small-vessel vasculitis, paraneoplastic small-vessel vasculitis, and inflammatory bowel disease vasculitis) [36]. Infectious arteritis includes bacterial, tuberculous, fungal, yeast, luetic (meningovascular 
syphilis), cysticercosis, rickettsia, and viral disorders [34]. Sarcoidosis and chemical and radiation arteritis should also be kept in mind.

Primary granulomatous angiitis of the CNS is a process usually restricted to vessels of $\leq 0.5 \mathrm{~mm}$ diameter, an arteriopathy that frequently is not visualized by angiography. But this inflammatory disorder may also involve large cerebral vessels [37]. The diagnosis of isolated angiitis of the CNS should be taken into consideration if the patient is young, presenting focal neurological signs, seizures, or constant severe headache. Without treatment (i.e., glucocorticoid) the clinical course of the GACNS, as may be expected, is often progressive. To establish a definitive diagnosis a leptomeningeal biopsy is necessary $[14,50]$. To decide which patients are candidates for biopsy it does depend on the gravity of the neurological picture, the functional importance of the cerebral artery to be biopsied, and lack of response to corticoid therapy.

Similar segmental narrowing was also reported in atypical cluster headache involving proximal portions of the middle and anterior cerebral arteries [51]. Additionally, hyperventilation induced by pain might cause vasoconstriction as well [52].

Several cases of women with preeclampsia-eclampsia and a history of sudden, severe headache accompanied by cerebral artery narrowing have been reported previously $[30,39,53]$. Preeclampsia is a frequent disorder characterized by hypertension, abnormal peripheral edema, and proteinuria. Most of the patients experience neurological signs and symptoms, such as headache, visual changes, confusion, disturbances of consciousness, or seizures. Such manifestations of the disease are identical to those of hypertensive encephalopathy. Clinical and radiographic signs of hypertensive encephalopathy probably are related to the consequences of an acute increase in systemic blood pressure, which, in turn, would affect the autoregulation of the cerebral vasculature.

Call et al. [39] reported four patients with reversible cerebral segmental vasoconstriction and concluded that their cases may represent a severe "clustering" form of migraine. These authors identified 12 other cases reported in the literature with clinical and angiographic similarities to their four cases, six occurring in the postpartum period, five being idiopathic, and one associated with an unruptured aneurysm. The cited authors also commented that the clinical feature of presentation resembles the rupture of an intracranial aneurysm, with a sudden, high-intensity headache associated with nausea, vomiting, and photophobia. In six cases biopsy or autopsy of one vasoconstricted artery disclosed no anatomic abnormalities.

On the other hand, the occurrence of vascular abnormality (narrowing) in young women and during the postpartum period, strongly suggests a hormonal influence exerted by sex steroids [39].

Cerebral postpartum angiopathy was described by Rascol et al. [54] in four women with distal arterial occlusion. None of them had arterial hypertension or renal disease. Hansen et al. [55] evaluated the effect of preeclampsia on cerebral artery blood flow velocity and concluded that cerebral vasospasm of the smaller diameter vessels is a major component of preeclampsia. Trommer et al. [30] reported that eclampsia might cause spasm of large- and medium-caliber cerebral vessels. They described the case of a 27-year-old woman, who 15 min postpartum complained of headache, nauseas, and epigastric pain and whose cerebral angiogram showed diffuse spasm.

Henry et al. [31] reported the case of a 34-year-old woman that during delivery, $10 \mathrm{~min}$ after receiving an intravenous administration of methylergometrine, experienced violent headache, associated with vomiting and arterial blood hypertension. Hours later the patients suffered seizures and mental confusion, with evolution to coma. An arteriography revealed marked segmental narrowing of the first middle cerebral artery branch. The authors postulated that the ergot-derived drug caused vasoconstriction through noradrenergic and serotoninergic actions. This class of drugs is particularly used during labor. Additionally, bromocriptine for lactation suppression in combination with a sympathomimetic agent caused hypertension, severe headache, seizures and cerebral vasospasm in a patient during the puerperium [56]. These facts may indicate that, during delivery or the postpartum period, patients are more susceptible to administration of vasoactive drugs and this, in turn, can precipitate arterial spasm.

Sudden surges in blood pressure may trigger a cerebral vasospasm, as also observed after adrenergic stimulation by the use of cocaine [25], by pheochromocytoma [29], or eclampsia [30]. Kaye and Fainatat [25] described the case of a cocaine addict, a 22-year-man, who developed rightsided headache associated with transient blurring of his vision. Four days later he presented weakness of the left side, and an arteriogram performed 5 days after the onset of the hemiparesis demonstrated the presence of narrowing of the supraclinoid portion of the right internal carotid and the occlusion of the proximal segment of the middle cerebral artery.

Patients with pheochromocytoma usually experience bilateral paroxystic episodes of bifrontal headache, radiating to temporal regions or secondarily generalizing, described as pulsating, moderate to severe in intensity. Lying down, moving, coughing, or straining makes the headache worse [57]. The above-mentioned features are similar to the headache described by patients with THARCV syndrome, which may suggest that sudden 
increases in arterial blood pressure in the presence of a cerebral arterial narrowing may trigger a headache attack [8].

Serdaru et al. [13] stated that during a migraine attack narrowing of the internal carotid artery usually involves either its extradural [18] or intracavernous [58] portion.

\section{Pathophysiology}

Two important questions should be answered: "What are the precipitants of vasoconstriction?" and "Is vasoconstriction the cause of pain?" Considering the vasospasm due to SAH and the biology of blood vessels, we could speculate about the pathophysiology of the supposed vasospasm found in THARCV syndrome.

The smooth muscle cell contraction occurring during SAH is still poorly understood. Vascular caliber may reflect adrenergic tone and sympathetic receptor sensitivity. Several factors participate in the regulation of vascular tone. The regulation of cerebral blood flow (CBF) is a fast and selective phenomenon and dramatic changes in blood flow or volume can be induced within a short period of time (seconds or minutes) regarding specific or regional brain areas either in normal [59] or abnormal (e.g., epilepsy) [60] physiologic conditions. The oscillations present in intracranial pressure are secondary to spontaneous changes in CBF velocity as a result of rhythmic changes in cerebral vessel diameter triggered by monoaminergic and serotonergic centers present in the brainstem [61].

In addition, arterial constriction followed by dilatation is postulated to be part of the pathophysiology mechanism of migraine [18]. The vascular endothelium synthesizes vasorelaxant substances, e.g., endothelium-derived relaxing factor (EDRF), acetylcholine (ACh), bradykinin, purines (i.e., ATP), histamine, vasopressin, substance $\mathrm{P}$, neurokinin $\mathrm{A}$ and $\mathrm{B}$, and prostaglandin $\mathrm{F} 2 \alpha$. On the contrary, endothelium-derived constricting factors may also be involved in the control of vascular tone, including serotonin, norepinephrine (NE), prostaglandin E2, thromboxane A2, leukotriene C4, endothelin (ET)-1, and ET-3. In addition, ACh releases EDRF. NE also induces release of EDRF and substance $\mathrm{P}$, which seem to attenuate the vasoconstrictor response to NE. EDRF was identified as being nitric oxide (NO), which is produced by neurons, glia, and endothelium. Sympathetic nerve varicosities release NE and other putative transmitters such as ATP, neuropeptide Y (constrictor), vasoactive intestinal peptide (dilators), and calcitonin gene-related peptide (dilator) [62].

Blood-borne NE and stimulation of sympathetic nerves do not affect significantly brain circulation [63]. After chronic trigeminal ganglionectomy there was an increase in the constrictor response of pial arteries to NE [64]. Also, inhibition of EDRF synthesis of or endothelial denudation enhances the vasoconstriction induced by NE. Likewise, acute hypertension allows the occurrence of important vasoconstrictor effects induced by sympathetic stimulation [65], indicating that, under certain circumstances, cerebral vessels may respond to noradrenergic stimuli. Interestingly, acute hypertension generates superoxide anion, which, in turn, inactivates EDRF [66]. This may reverse the AChinduced cerebral arterial dilatation and augment cerebral vasoconstriction induced by $\mathrm{NE}$, or sympathetic stimulation.

High levels of vasoactive and spasmogenic substances are present in the CSF and plasma of patients with SAH and vasospasm [22]. In the presence of SAH, endotheliumdependent relaxation is impaired by the production of potent endothelium-derived contracting factors (cyclooxygenase products of arachnoid acid and ET). Endothelin, a 21 amino acids peptide, has very potent and long-lasting constrictive effects. Many lines of evidence suggest that ET may be intimately involved in the genesis of the cerebral vasospasm. The plasma concentration of ET-1 is higher in patients with vasospasm than in patients without symptomatic vasospasm, with the peak concentration coinciding with the occurrence of the vasospasm. In isolated human cerebral artery segments, ET produced intense and sustained vascular constriction, which was inhibited by sodium nitroprusside or verapamil. The enhanced vascular tone induced by ET is resistant to NE antagonists, serotonin, isoproterenol, histamine, $\mathrm{ACh}$, and angiotensin II. In canine basilar artery, calcium-channel blockers such as nicardipine and papaverine reversed the contraction induced by ET-1. The arterial contraction induced by both $\mathrm{NE}$ and serotonin is amplified by the addition of low concentrations of ET-1 [22]. During experimental SAH the cerebral vessels are hyperreactive to ET, indicating that in a given situation of higher reactivity of a particular segment of the cerebral arterial system (by a reason not yet known) sudden release of NE, serotonin, or any other vasoconstrictor into the circulation could precipitate a severe and long-lasting segmental arterial constriction. Or yet again, the lack of action of endogenous substances with vasodilator properties would facilitate vasoconstriction.

Nitric oxide also inhibits ET-1 synthesis. A close interaction between ET (a vasoconstrictor) and NO (a vasodilator) appears to take place and to play a major physiologic role in the control of CBF and vessel caliber. So, any disturbance that may occur in the equilibrium between constrictor and dilator factors could generate arterial spasm.

Endothelin-1 levels increase during [67-69] and between migraine attacks [67], suggesting that the peptide is implicated in the physiopathogenesis of migraine. It was reported that a variant of the ETa receptor gene modulates 
the risk for migraine [70]. This may imply that migraineurs with qualitatively or quantitatively altered ETa receptor may present dysregulation of arterial tone, resulting in inadequate dilatation or constriction of cerebral vessels in response to different stimuli.

Supporting the hypothesis that NO might also participate in the genesis of pain, nitroglycerin, by provoking vasodilatation via NO formation, is able to induce in healthy subjects an immediate, short-lasting, bilateral fronto-temporal and pulsating headache, that can be aggravated by routine physical activity [71]. Intriguingly, nitroglycerin causes a more severe pain in migraine patients [72, 73]. Alteration of intracranial vessel tone and regional instability of the CBF were documented in migrainous patients during the headache-free interval [74-77]. This suggests that cerebral arteries of migraineurs might react differently to diverse stimuli. If so, this fact may justify the frequent occurrence of the syndrome in migranous subjects.

Buckele et al. [78] described the case of a 16-year-old girl experiencing an attack associated with headache, when she suddenly felt tired and faint (not well characterized if it was abrupt or severe) that was repeated several times within a period of four months. Such attacks were thought to be the expression of migraine events, in view of the slow progress of some episodes, accompanied by fatigue, drowsiness, and cold hands. An arteriogram revealed widespread intense intracranial vasospasm. The clinical course progressed to death due to intracranial hypertension and cerebral edema. No evidence of primary vascular disease was found at autopsy. This case led to the assumption that the THARCV syndrome may eventually course with atypical headache episodes or even without any pain at all, including a number of young adult patients with stroke. Most but not all the headaches associated with reversible cerebral vasoconstriction have the characteristics of thunderclap headache according to most recent findings [79]. Such reported cases were not included in our analyzed series to study better the profile of typical patients with THARCV syndrome.

Dr. Robert H. Ackerman [37] commented about the multiple areas of narrowing, beading, and sausage-shaped dilation of cerebral vessels observed during angiography of patient \# 3 in Table 3 as follows: "These segmental changes are nonspecific signs that can be found in a number of primary and secondary disorders affecting the pial vessels, which lie in the subarachnoid space and receive an investiture of pia as they enter the brain." These data suggest the possibility of a local relationship between CSF, arterial vessels, and brain parenchyma to explain segmental vasospasm.

Interestingly, the pattern of the cerebral arterial spasm generated by a number of different etiologic causes has the particular feature of being segmental in nature. In addition, it is a short lasting (hours or days), reversible phenomenon.
This may suggest that the constriction of a major cerebral artery is segmental and does not involve the entire extension of the vessel, particularly during high-intensity stimulation. Are those localized vascular constrictions observed in intracranial arteries during the conditions discussed above anatomic-functional sphincters controlling local blood flow? Or is the vasospasm occurring in the THARCV syndrome primarily a sphincter disturbance?

Precipitating factors, such as sexual activity, may induce vascular changes with profound hemodynamic fluctuations, which may trigger the pain if an arterial narrowing is present. In this regard, during continuous monitoring of intra-arterial blood pressure Mann et al. [80] documented that during coitus, peaks values of up to $300 / 175 \mathrm{mmHg}$ were registered, with a mean of 237/138 mmHg for men and of 216/ $127 \mathrm{mmHg}$ for women, in hypertensive subjects.

Tricyclic antidepressants (i.e., amitriptyline), potent inhibitors of the neuronal uptake of NE, systemically administered to humans caused a reduction of the whole body NE spillover to plasma, due to the reduction in nerve firing rates. Propranolol had a similar effect on NE overflow [81]. Propranolol, by blocking vascular $\beta$-receptors, could impair the anticipated vasodilatation induced by activating $\beta$-adrenergic receptors. So, propranolol could facilitate a predominance of the vasoconstrictor effect. Nonselective beta-blockers can also have the adverse effect of increasing platelet aggregability. In this regard, the association of propranolol with stroke in migraineurs has been mentioned previously [82, 83]. Lance and Goadsby [84] advise to avoid the use of beta-blockers in migraineurs with prolonged aura or severe focal neurological symptoms. In this respect, three of the patients presented in Table 3 (\# 4, 12, and 21) were under prophylactic use of propranolol, and patient \# 3 had aggravation of the neurological manifestation after introduction of propranolol in her prescription. Similar vascular changes in reactivity to endogenous substances can happen with the therapeutic use of amitriptyline. By the way, two patients of the 11 cases described as isolated angiitis of the CNS [14] were using either propranolol (case 6) or tricyclics (case 9). Do these pharmacological substances facilitate the development of cerebral vasospasm? This question remains to be answered.

The diagnosis of a growing number of patients with the THARCV syndrome is anticipated nowadays, mainly with the broad use of the harmless CT or MR angiography and a greater knowledge of the syndrome. This study was previously presented at the Brazilian Headache Congress in 2002 [85] as a new headache syndrome named "Abrupt severe headache associated with segmental artery narrowing (ASHCAN)" $[8,86]$ and since then several other cases of the syndrome have been reported [44, 79, 87-89].

In conclusion, the present article was written in an attempt to better characterize the profile of the patients 
with THARCV syndrome. This syndrome is a neurological disturbance; perhaps more frequent than expected, preferentially affecting migrainous middle-aged women, with an unpredictable prognosis, either having a benign course or leading to stroke.

\section{Conflict of interest None.}

\section{References}

1. Snyder BD, McClelland RR (1978) Isolated benign cerebral vasculitis. Arch Neurol 35:612-614

2. Dodick DW, Brown RD Jr, Britton JW, Huston JIII (1999) Nonaneurysmal thunderclap headache with diffuse, multifocal, segmental, and reversible vasospasm. Cephalalgia 19:118-123

3. Garg RK (2001) Recurrent thunderclap headache associated with reversible vasospasm causing stroke. Cephalalgia 21:78-79

4. Delvaux V, Vandenheede M, Schoenen J (2000) Explosive "thunderclap" headaches: should they be taken seriously? Rev Med Liege 55:910-914

5. Sturm JW, Macdonell RA (2000) Recurrent thunderclap headache associated with reversible intracerebral vasospasm causing stroke. Cephalalgia 20:132-135

6. Day JW, Raskin NH (1986) Thunderclap headache: symptom of unruptured cerebral aneurysm. Lancet 2:1247-1248

7. Slivka A, Philbrook B (1995) Clinical and angiographic features of thunderclap headache. Headache 35:1-6

8. Valença MM, Valença LP, Bordini CA, da Silva WF, Leite JP, Antunes-Rodrigues J, Speciali JG (2004) Cerebral vasospasm and headache during sexual intercourse and masturbatory orgasms. Headache 44:244-248

9. Jackson M, Lennox G, Jaspan T, Jefferson D (1993) Migraine angiitis precipitated by sex headache and leading to watershed infarction. Cephalalgia 13:427-430

10. Kapoor R, Kendall BE, Harrison MJG (1990) Persistent segmental cerebral artery constriction in coital cephalgia. J Neurol Neurosurg Psychiatry 53:266-267

11. Kawagoe KE, Carvalho DS, Oliveira ASB (1999) Headache associated with sexual activity. Rev Neurociências 7:89-91

12. Silbert PL, Hankey GJ, Prentice DA, Apsimon HT (1989) Angiographically demonstrated arterial spasm in a case of benign sexual headache and benign exertional headache. Aust NZ J Med 19:466-468

13. Serdaru M, Chiras J, Cujas M, L'Hermitte F (1984) Isolated benign cerebral vasculitis or migranous vasospasm? J Neurol Neurosurg Psychiatry 47:73-76

14. Crane R, Kerr LD, Spiera H (1991) Clinical analysis of isolated angiitis of the central nervous system. A report of 11 cases. Arch Intern Med 151:2290-2294

15. Monteiro JMP, Carneiro AL, Lima AFB, Lopes JRC (1985) Migraine and cerebral infarction; three case studies. Headache 25:429-433

16. Rothrock JF, Walicke P, Swenson MR, Lyden PD, Logan WR (1988) Migrainous stroke. Arch Neurol 45:63-67

17. Rothrock JF (1993) Migrainous stroke. Cephalalgia 13:231

18. Dukes MT, Vieth RG (1964) Cerebral arteriography during migraine and headache. Neurology 14:636-639

19. Olesen J, Friberg L, Skyhoj-Olsen T et al (1990) Timing and topography of cerebral blood flow, aura and headache during migraine attacks. Ann Neurol 28:791-798

20. Lauritzen M (1994) Pathophysiology of the migraine aura. The spreading depression theory. Brain 117:199-210
21. Thomas TD, Harpold GJ, Troost BT (1990) Cerebrovascular reactivity in migraineurs as measured by transcranial Doppler. Cephalalgia 10:95-99

22. Zimmermann M, Seifert V (1998) Endothelin and subarachnoid hemorrhage: an overview. Neurosurgery 43:863-876

23. Lighnelli GJ, Buchheit WA (1971) Angiitis in drug abusers. N Engl J Med 284:112-113

24. King J, Richards M, Tress B (1978) Cerebral arteritis associated with heroin abuse. Med J Aust 2:444-445

25. Kaye BR, Fainstat M (1987) Cerebral vasculitis associated with cocaine abuse. JAMA 258:2104-2106

26. Bloomfield SM, Sonntag VKH (1985) Delayed cerebral vasospasm after uncomplicated operation on an unruptured aneurysm: case report. Neurosurgery 17:792-796

27. Wilkins RH, Odom GL (1970) Intracranial arterial spasm associated with craniocerebral trauma. J Neurosurg 32:626-633

28. MacKenzie RA, Forbes GS, Karnes WE (1981) Angiographic findings in herpes zoster arteritis. Ann Neurol 10:458-464

29. Armstrong CSF, Hayes CGJ (1961) Segmental cerebral constriction associated with pheochromocytoma. Report of a case with arteriograms. J Neurosurg 18:843-846

30. Trommer BL, Homer D, Mikhael MA (1988) Cerebral vasospasm and eclampsia. Stroke 19:326-329

31. Henry PY, Larre P, Aupy M, Lafforgue JL, Orgogozo JM (1984) Reversible cerebral arteriopathy associated with the administration of ergot derivatives. Cephalalgia 4:171-178

32. Kwentus J, Kattah J, Koppicar M, Potolicchio SJ (1985) Complicated migraine and cerebral angiography: a report of an unusual adverse reaction. Headache 25:240-245

33. Midgard R, Hofstad H (1986) Unusual manifestations of nervous system Borrelia burgdorferi infection. Arch Neurol 20:362-364

34. Ferris EJ, Levine HL (1973) Cerebral arteritis: Classification. Radiology 109:327-341

35. Pomper MG, Miller TJ, Stone JH, Tidmore WC, Hellmann DB (1999) CNS vasculitis in autoimmune disease: MR-imaging findings and correlation with angiography. AJNR Am J Neuroradiol 20:75-85

36. Jennette JC, Falk RJ (1997) Small-vessel vasculitis. N Eng J Med $337: 1512-1523$

37. Case records of the Massachusetts General Hospital (case 351985). N Engl J Med 313:566-575

38. Fisher CM (1986) Late-life migraine accompaniments-Further experience. Stroke 17:1033-1042

39. Call GK, Fleming MC, Sealfon S, Levine H, Kistler JP, Fisher CM (1988) Reversible cerebral segmental vasoconstriction. Stroke 19:1159-1170

40. Solomon S, Lipton RB, Harris PY (1990) Arterial stenosis in migraine: spasm or arteriopathy? Headache 30:52-61

41. Spierings ELH (1990) Angiographic changes suggestive of vasospasm in migraine complicated by stroke. Headache 30:727728

42. Schulman EA, Hershey B (1991) An unusual angiographic picture in status migrainosus. Headache 31:396-398

43. Slivka A, Philbrook B (1995) Clinical and angiographic features of thunderclap headache. Headache 35:1-6

44. Calabrese LH, Dodick DW, Schwedt TJ, Singhal AB (2007) Narrative review: reversible cerebral vasoconstriction syndromes. Ann Intern Med 146:34-44

45. Headache Classification Committee of the International Headache Society (2004) The international classification of headache disorders. Cephalalgia 24(supp 1):1-151

46. Silberstein SD, Lipton RB, Goadsby PJ (1998) Headache in Clinical Practice. ISIS Medical Media, Oxford

47. Kwentus J, Kattah J, Koppicar M, Potolicchio SJ (1985) Complicated migraine and cerebral angiography: a report of an unusual adverse reaction. Headache 25:240-245 
48. Abbott RJ, van Hille P (1986) Thunderclap headache and unruptured cerebral aneurysm. Lancet ii:1459

49. Tang-Wai DF, Phan TG, Wijdicks EFM (2001) Hypertensive encephalopathy presenting with thunderclap headache. Headache 41:198-200

50. Calabrese DO, Mallek J (1987) Primary angiitis of the central nervous system. Medicine 67:20-39

51. Garnic JD, Schellinger D (1983) Arterial spasm as a finding intimately associated with onset of vascular headache. Neuroradiology 24:273-276

52. Hachinski VC, Oleson J, Norris JW, Larsen B, Enevoldsen E, Lassen NA (1977) Cerebral hemodynamics in migraine. J Can Neurol Sci 4:245-251

53. Masuzawa T, Shinoda S, Furuse M, Nakahara N, Abe F, Sato F (1983) Cerebral angiographie changes on serial examination of a patient with migraine. Neuroradiology 24:277-281

54. Rascol A, Guiraud B, Manelfe C, Clanet C (1980) Accidents vasculaires cerebraux de la grossesse et du post partum. In: Cerebrovascular Diseases. II Conference de la Salpetriere. Paris, JB Bailliere, pp 85-127

55. Hansen WF, Burnham SJ, Svendsen TO, Katz VL, Thorp JM Jr, Hansen AR (1996) Transcranial Doppler findings of cerebral vasospasm in preeclampsia. J Matern Fetal Med 5:194-200

56. Kulig K, Moore LL, Kirk M, Smith D, Stallworth J, Rumack B (1991) Bromocriptine-associated headache: possible life-threatening sympathomimetic interaction. Obstet Gynecol 78:941-943

57. Lance JW, Hinterberger H (1976) Symptoms of pheochromocytoma, with particular reference to headache, correlated with catecholamine production. Arch Neurol 33:281-288

58. Bickerstaff ER (1964) Ophthalmoplegic migraine. Rev Neurol $110: 582-588$

59. Ito H, Takahashi K, Hatazawa J, Kim S-G, Kanno I (2001) Changes in human regional cerebral blood flow and cerebral blood volume during visual stimulation measured by positron emission tomography. J Cereb Blood Flow Metab 21:608-612

60. Wichert-Ana L, Velasco TR, Terra-Bustamante VC, Araujo D Jr, Junior VA, Kato M, Leite JP, Assirati JA, Machado HR, Bastos AC, Sakamoto AC (2001) Typical and atypical perfusion patterns in periictal SPECT of patients with unilateral temporal lobe epilepsy. Epilepsia 42:660-666

61. Sliwka U, Harscher S, Diehl RR, van Schayck R, Niesen WD, Weiller C (2001) Spontaneous oscillations in cerebral blood flow velocity give evidence of different autonomic dysfunctions in various types of headache. Headache 41:157-163

62. Mulvany MJ, Aalkær C (1990) Structure and function of small arteries. Physiol Rev 70:921-961

63. Baumbach GL, Heistad DD (1983) Effects of sympathetic stimulation and changes in arterial pressure on segmental resistance of cerebral vessels in rabbits and cats. Circ Res 52:527-533

64. Moskowitz MA, Wei EP, Saito K, Kontos HA (1988) Trigeminalectomy modifies pial arteriolar responses to hypertension or norepinephrine. Am J Physiol 255:H1-H6

65. Tamaki K, Heistad DD (1986) Response of large and small cerebral arteries to sympathetic stimulation during acute hypertension. Hypertension 8:911-917

66. Wei EP, Kontos HA, Christman CW, deWitt DS, Povlishock JW (1985) Superoxide generation and reversal of acetylcholineinduced cerebral arteriolar dilation after acute hypertension. Cir Res 57:781-787

67. Kallela M, Färkkilä M, Saijonmaa O, Fyhrquist F (1998) Endothelin in migraine patients. Cephalalgia 18:329-332

68. Gallai V, Sarchielli P, Firenze C et al (1994) Endothelin 1 in migraine and tension-type headache. Acta Neurol Scand 89:47-55

69. Hasselblatt M, Kohler J, Volles E, Ehrenreich H (1999) Simultaneous monitoring of endothelin-1 and vasopressin plasma levels in migraine. NeuroReport 10:423-425
70. Tzourio C, El Amrani M, Poirier O, Nicaud V, Bousser M-G, Alpérovitch A (2001) Association between migraine and endothelin type A receptor (ETA-231 A/G) gene polymorphism. Neurology 56:1273-1277

71. Schmetterer L, Wolzt M, Graselli U, Findl O, Strenn K, Simak S, Kastner J, Eichler H-G, Singer EA (1997) Nitric oxide synthase inhibition in the histamine headache model. Cephalalgia 17:175182

72. Olesen J, Iversen HK, Thomsen LL (1993) Nitric oxide supersensitivity. A possible mechanism of migraine pain. NeuroReport 4:1027-1030

73. Thomsen LL, Iversen HK, Brinck TA, Olesen J (1993) Arterial supersensitivity to nitric oxide in migraine sufferers. Cephalalgia 13:395-399

74. Thomas TD, Harpold GJ, Troost BT (1990) Cerebrovascular reactivity in migraineurs as measured by transcranial Doppler. Cephalalgia 10:95-99

75. Sakai F, Meyer JS (1979) Abnormal cerebrovascular reactivity in patients with migraine and cluster headaches. Headache 19:257266

76. Lagrèze HL, Dettmers C, Hartmann A (1988) Abnormalities of interictal cerebral perfusion in classic but not common migraine. Stroke 19:1108-1111

77. Totaro R, Marini C, De Matteis G, Di Napoli M, Carolei A (1997) Cerebrovascular reactivity in migraine during headachefree intervals. Cephalalgia 17:191-194

78. Buckle RM, du Boulay G, Smith B (1964) Death due to cerebral vasospasm. J Neurol Neurosurg Psychiat 27:440-444

79. Ducros A, Boukobza M, Porcher R, Sarov M, Valade D, Bousser MG (2007) The clinical and radiological spectrum of reversible cerebral vasoconstriction syndrome. A prospective series of 67 patients. Brain 130:3091-3101

80. Mann S, Millar Craig MW, Gould BA, Melville DI, Raftery EB (1982) Coital blood pressure in hypertensives cephalgia, syncope, and the effects of beta-blockade. Br Heart J 47:84-89

81. Esler M, Jennings G, Lambert G, Meredith I, Horme M, Eisenhofer G (1990) Overflow of catecholamine neurotransmitters to the circulation: source, fate, and functions. Physiol Rev 70:963985

82. Bardwell A, Trott JA (1987) Stroke in migraine as a consequence of propranolol. Headache 27:381-383

83. Mendizabal JE, Greiner F, Hamilton WJ, Rothrock JF (1997) Migrainous stroke causing thalamic infarction and amnesia during treatment with propranolol. Headache 37:594-596

84. Lance JW, Goadsby PJ (1998) Mechanism and Management of Headache, 6th edn. Butterworth-Heinemann, Oxford

85. Valença MM, Bordini CA, Andrade-Valença LPA, Leite JP, Antunes-Rodrigues J, Speciali JC (2002) Abrupt severe headache associated with cerebral artery narrowing (ASHCAN): a new headache syndrome. Migrâneas Cefaléias 5:91

86. Valença MM, Costa J, Silva WF, Andrade-Valença LPA, Wichert-Ana L, Leite JP, Bordini CA, Speciali JG, AntunesRodrigues J (2002) Cerebral arterial narrowing: differential diagnosis, pathophysiology and correlation with headache syndromes. Neurobiologia 65:3-12

87. Kowacs F, Aesse FF, Alencastro LC, Fernandes ML (2006) Cerebral reversible vasoconstriction syndrome in a thunderclap headache patient-spiral CT vascular and perfusion abnormalities. Migrâneas Cefaléias 9:84-85 (Portuguese)

88. Chen SP, Fuh JL, Lirng JF, Chang FC, Wang SJ (2006) Recurrent primary thunderclap headache and benign CNS angiopathy: spectra of the same disorder? Neurology 67:2164-2169

89. Gerretsen P, Kern RZ (2007) Reversible cerebral vasoconstriction syndrome or primary angiitis of the central nervous system? Can J Neurol Sci 34:467-477 